\title{
High prevalence of seasonal affective disorder among persons with severe visual impairment
}

Helle Østergaard Madsen, Henrik Dam and Ida Hageman

\section{Background}

Light severely affects the occurrence of seasonal affective disorder (SAD)

\section{Aims}

To compare the prevalence of SAD in persons with severe visual impairment and persons with full sight, and in persons with severe visual impairment with or without light perception.

\section{Method}

This cross-sectional study assessed the Global Seasonality Score (GSS) and the prevalence of SAD among 2781 persons with visual impairment and 4099 persons with full sight using the Seasonal Pattern Assessment Questionnaire (SPAQ).

\section{Results}

Respondents with visual impairment had significantly higher GSS and prevalence of SAD compared with full sight controls, $P<0.001$. Light perception respondents were more vulnerable to seasonal change than both full sight and no light perception respondents.

\section{Conclusions}

The study showed a highly significant association between visual impairment and SPAQ-defined SAD parameters, supporting the hypothesis that decreased retinal light input plays a role in the pathogenesis of SAD.

\section{Declaration of interest}

None.

\section{Copyright and usage}

(c) The Royal College of Psychiatrists 2016.
In 1984 the syndrome of recurrent wintertime increases in sleep duration and appetite along with lowering of mood and energy levels was described and named seasonal affective disorder (SAD). ${ }^{1}$ The pathogenesis of SAD is complex and includes both biological and psychological factors. Climatic factors such as global radiation, length of day, temperature and hours of sunshine seem to be important for the annual onset of the disease. ${ }^{2}$ The main biological pathogenetic theories concern disturbances in biological rhythms and/or neurotransmitter levels, genetic variations and retinal subsensitivity, ${ }^{3}$ in all of which light is involved. Moreover, light plays a major role in the treatment of SAD. The clinical effect of therapy with bright white light for SAD has been demonstrated in a 2005 meta-analysis finding effect sizes equivalent to those of antidepressant pharmacotherapy, with a reported effect size of 0.84 compared with varying placebo conditions using suboptimal light intensities. ${ }^{4}$ It is essential that the light is directed towards the uncovered eyes of the receiver. ${ }^{5}$ Depending on the modality of measurement, studies have reported both increased and decreased retinal sensitivity to light in patients with SAD compared with healthy controls. ${ }^{6-8}$ One study reported a decrease in rod and cone function in patients with SAD during wintertime which seems fully reversible with light therapy. ${ }^{9}$ Moreover, SAD and seasonal changes in sleep patterns have been reported to be associated with a missense variant of the gene encoding the retinal photopigment melanopsin. ${ }^{10,11}$ Melanopsin is located in recently detected intrinsically photosensitive retinal ganglion cells (ipRGCs) which are involved in the projection of changes in the ambient light intensity to the brain. ${ }^{12,13}$ These photoreceptors and their projections to the brain do not seem to be involved in conscious sight, e.g. information about objects in the visual field, but more likely they represent a part of the so-called non-image forming visual system. This system entrains the circadian clock located in the suprachiasmatic nucleus of the hypothalamus and is therefore involved in circadian homeostasis. One measure reflecting circadian homeostasis is the pattern of nocturnal melatonin secretion which can be suppressed by retinal light stimulation. ${ }^{14}$ A 20-year-old study showed light-induced melatonin suppression in three profoundly blind people who did not report signs of circadian misalignment ${ }^{15}$ but otherwise it is only recently that these issues have been directly investigated in persons with visual impairment. There are now strong indications that the non-image forming visual system can remain fully functional despite a complete absence of conscious visual perception. One of the major pathogenetic hypotheses on $\mathrm{SAD}$, the phase shift hypothesis, categorises the syndrome as a circadian disturbance.

Although light input clearly plays an important role in both pathogenesis and treatment of the syndrome, there exists no epidemiological studies linking known decreased visual capacity and SAD. Originally, Rosenthal et al described two cases of SAD in blind individuals but the area has not been explored further. ${ }^{16}$ Our study is the first to directly address an association between severe visual impairment and the affective and behavioural parameters associated with SAD. Besides the given neurobiological implications of this question, we find it of clinical importance to map an affective syndrome closely connected to light input in a population with known severe visual dysfunction in order to increase attention on the syndrome and treatment alternatives if needed.

The aims of our study were: (a) to assess the prevalence of SAD in a population of blind and severely visually impaired persons (visual impairment); (b) to compare the findings with a control group without visual impairment (full sight); and (c) to clarify whether the prevalence of SAD is associated with the presence (light perception) or absence of conscious light perception (no light perception).

\section{Method}

\section{Population}

All members of the Danish Association of the Blind (DAB) between 18 and 65 years were invited to participate in the study. $\mathrm{DAB}$ membership requires a medically documented severe visual 
impairment resulting in a corrected sight less than 6/60 Snellen visual acuity. All 2781 invited persons were thus socially or practically blind according to Danish definitions.

A control group of 4099 persons was identified through the Danish Central Register of Persons (CPR register).

\section{Subgroups}

As a part of the questionnaire, DAB members were to state their visual ability, i.e. their ability to perceive light, to determine source and direction of light or to count fingers at a distance of $1 \mathrm{~m}$. These parameters are used in the clinical evaluation of sight when a Snellen chart is no longer applicable. On the basis of these questions, DAB members (visual impairment) were divided into two subgroups according to their ability to perceive light; a no light perception subgroup of profoundly blind individuals who stated they had no ability to see light, to determine source and direction of light or to count fingers at a distance of $1 \mathrm{~m}$ and a subgroup with maintained light perception who stated that they were able to perceive light. The majority of this latter group was also able to determine source and direction of light and to count fingers at distance of $1 \mathrm{~m}$ and the light perception subgroup as a whole was thus rather heterogeneous. Besides a renewed clinical evaluation, no other data on current visual status were attainable.

Control participants were excluded if they reported having severe visual impairment (Snellen visual acuity less than 6/60) or any visual impairment or eye disease besides common myopia, hypermetropia or astigmatism. By this definition, persons with mild correctable visual impairment were regarded as fully sighted controls.

\section{Instrument}

A Danish translation of the Seasonal Pattern Assessment Questionnaire (SPAQ) was used to evaluate seasonal variation. Originally, the SPAQ was developed by the Rosenthal group to rate variation from one season to another within the six items - sleep duration, mood, social activity, appetite, weight and energy levels - in order to set case identification criteria for screening purposes. ${ }^{17}$ Each item is rated from no variation ( 0 points) to extremely marked variation (4 points). The sum score yields the Global Seasonality Score (GSS) of a maximum of 24 points. The GSS cut-off for case identification is set at 11 or higher. To define a winter case, the month of maximum discomfort must be between November to February with no report of discomfort during summer months. In addition to the score, the criteria for SPAQ-defined SAD case identification require the individual to perceive the seasonal variation as a problem of at least a moderate degree.

The SPAQ also sets criteria for a milder form of the syndrome, subsyndromal SAD (sSAD). SPAQ criteria for SSAD are (a) a GSS of 11 or higher and the problem being of no or minor degree, or (b) a GSS of 9 or 10 and seasonal changes being perceived as a problem or not. The timing of the problem is the same as for SAD.

\section{Survey}

In late autumn 2010, all $2781 \mathrm{DAB}$ members between 18 and 65 years received a copy of the SPAQ in enlarged print, Braille font or on audio disc, according to the DAB registry of preferred communication. The letter contained a stamped envelope, a contact telephone number and email address to which replies could be returned. The invitation stated that the person would be contacted by telephone and offered a telephone interview if acceptance or refusal to participate was not received within 2 months of the send-out.
A similar survey was performed among 4099 control participants identified through the Danish CPR register at the corresponding time, the consecutive winter season. In the control group the questionnaires were re-sent to non-responders after 1 month to increase response before telephone follow-up.

In both surveys, the invitation to the study included a brief introduction to SAD symptomatology and treatment. Information was also given that the study was investigating seasonality in visually impaired persons compared with fully sighted persons.

For further details please see our protocol article. ${ }^{18}$

\section{Statistics}

A general linear regression model was applied to test the effect of severe visual impairment on GSS and to adjust for the uneven distribution of background parameters between the visual impairment and full sight groups. The primary model contained population (visual impairment or full sight), gender, age and interview method (mail or telephone), and all possible interactions among these four factors. Significant factors included in the final model were gender, population, interview method and the interaction of gender and age $(P<0.01)$.

To evaluate the effects of conscious light perception on GSS, a general linear regression model was constructed to adjust for the uneven distribution of background factors between the full sight, light perception and no light perception subgroups. The primary model contained vision status (no light perception, light perception or full sight), age, gender and interview method (mail or telephone) and all possible interactions between the four variables. Significant factors included in the final model were gender, vision status, interview method and the interaction of gender and age $(P<0.01)$.

When assessing the importance of visual status for the prevalence of SPAQ-defined SAD, the four above-mentioned variables and possible interactions were included in a logistic regression model. Significant factors in this model were the main effects of age, gender, interview method and vision status (visual impairment/full sight or no light perception/light perception/full sight).

All data were analysed in SPSS, version 20.

\section{Ethics}

The study was approved by the Danish Data Protection Agency. The study was consulted with the local ethics committee who certified that the study did not need ethics approval according to Danish law as there were no biological material or intervention involved in the project.

\section{Results}

\section{Response}

Of the 2781 DAB members, 992 persons initially returned completed questionnaires and 97 declined the invitation to participate. All remaining members were contacted by telephone and of these, 655 completed the interview. Of the 1037 nonresponders, roughly a third could not be reached by several telephone attempts, a third was not registered with a valid telephone number and a third was reached but the respondent was either unwilling or unable to participate due to death, competing illnesses/disabilities or insufficient Danish or English language. The total response rate was 59.2\% (1647 persons) and only $9 \%$ (249 persons) directly refused to participate in the survey (Fig. 1). In the control group, 4099 persons were invited to participate. Initially, 1988 responses were received. A valid telephone number could not be identified for 556 persons. Telephone follow-up 


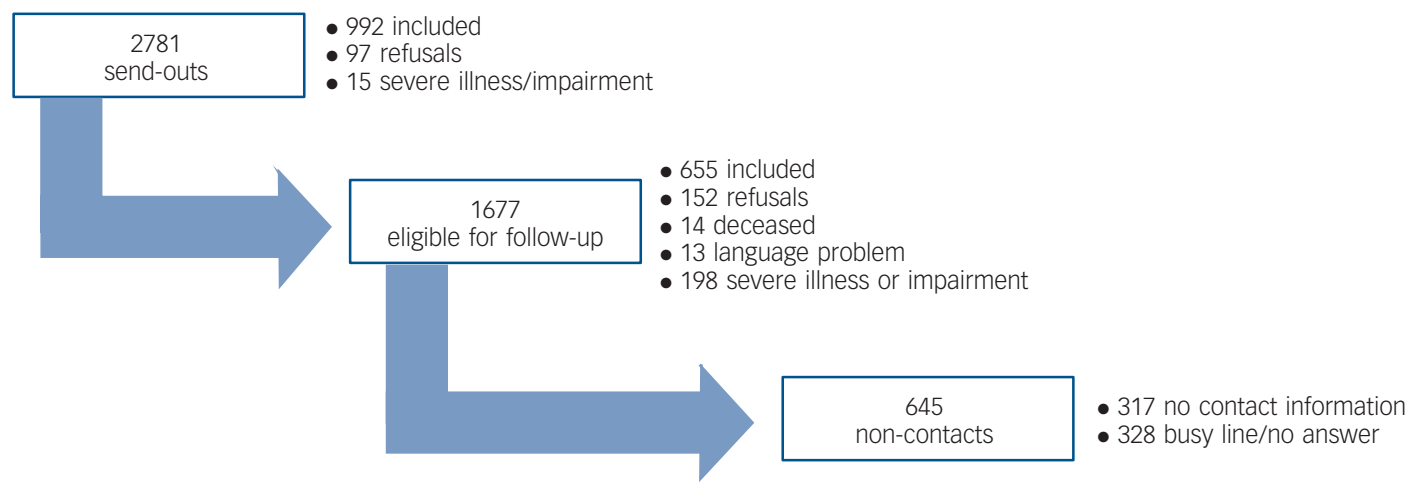

Fig. 1 Response in population with visual impairment

among the remaining non-responders resulted in 431 interviews. Among the primary respondents, 148 claimed to have a severe visual impairment and were thus excluded from the sample. With these excluded, a total response rate of $57 \%$ (2271) was reached (Fig. 2).

\section{Descriptives}

Of the 1647 visual impairment respondents, 67 persons did not report their level of visual impairment sufficiently and were thus included in the overall comparison between visually impaired and fully sighted populations but excluded from subgroup analyses.

A total of 251 persons reported to have no conscious perception of light. These respondents were significantly younger but had similar distributions of gender and interview method when compared with the light perception subgroup of 1329 persons (Table 1). Approximately two-thirds of this latter group reported a maintained ability to count fingers at a distance of $1 \mathrm{~m}$, a third reported maintained ability to determine direction of light and only a small number reported only to be able to perceive a light stimulus.

The 2271 full sight respondents all reported to have corrected sight better than 6/60 Snellen visual acuity. The full sight group was 3 years older (median) and the proportion of women was higher than in the visual impairment group.

In total, 68 respondents stated to be at worst discomfort during a summer month and were excluded.

\section{Seasonality in persons with severe visual impairment and persons with full sight}

When applying the regression models to the data it appeared that visual impairment respondents had significantly higher GSS and odds for SPAQ-defined SAD than the full sight control respondents (Table 2). The average difference in score was 1.8 points and highly significant $(P<0.001)$. In both populations, women had increased scores compared with men and GSS was negatively correlated to age for both men and women. These associations were similar in both populations. Telephone interviews resulted in significantly lower GSS compared with mailed questionnaires. The threefold increase in odds for fulfilling SPAQ-defined SAD criteria among visual impairment respondents compared with full sight controls was highly significantly $(P<0.001)$. As expected, odds significantly increased with younger age, female gender and mail reply.

\section{Seasonality in persons with no light perception, maintained light perception or full sight}

Light perception respondents were more vulnerable to seasonal change in terms of both GSS and prevalence of SPAQ-defined SAD compared with no light perception and full sight respondents. Compared with full sight controls, light perception respondents had a 1.9 points higher GSS $(P<0.001)$ and a threefold increase in odds for SPAQ SAD $(P<0.001)$.

No light perception respondents exhibited an intermediate degree of seasonality, being significantly less seasonal than light perception respondents. No light perception respondents were slightly more seasonally affected than full sight respondents with a 0.6 point higher GSS $(P=0.05)$ and a twofold increase in odds for case identification $(P=0.002$; Table 3$)$.

\section{Discussion}

To our knowledge, this study is the first to report a highly significant association between visual impairment and SPAQ-defined SAD.

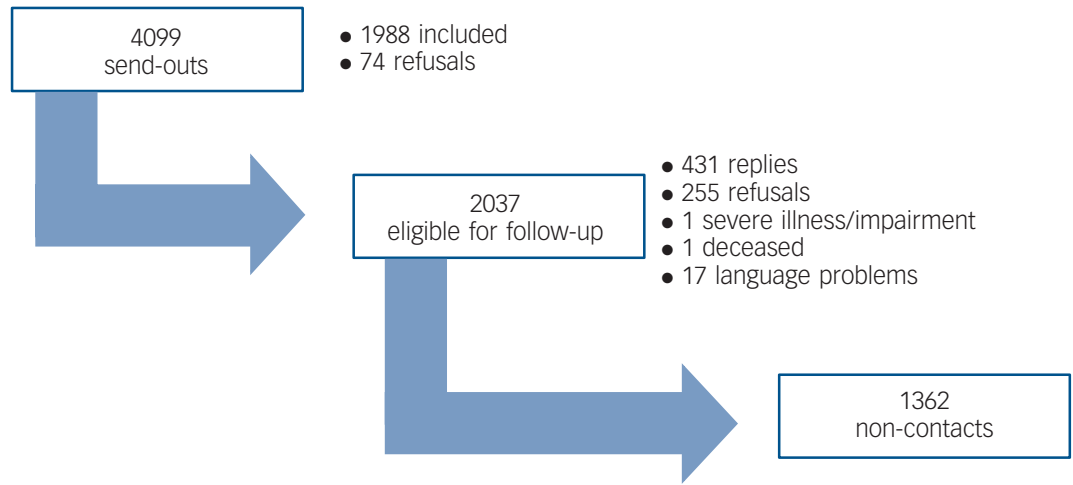




\begin{tabular}{|c|c|c|c|c|c|c|c|c|c|c|c|}
\hline & $n$ & $\begin{array}{c}\text { Female, } \\
\%\end{array}$ & $\begin{array}{l}\text { Age } \\
\text { median }\end{array}$ & $\begin{array}{c}\text { Telephone } \\
\text { interview, \% }\end{array}$ & $\begin{array}{c}\text { GSS } \\
\text { median }\end{array}$ & $\begin{array}{l}\text { GSS } \\
\text { mean }\end{array}$ & s.d. & $\begin{array}{l}\text { SPAQ } \\
\text { SAD } \%\end{array}$ & $\begin{array}{c}\text { SPAQ SAD } \\
n\end{array}$ & $\begin{array}{l}\text { SPAQ } \\
\text { SSAD } \%\end{array}$ & $\begin{array}{c}\text { SPAQ SSAD } \\
n\end{array}$ \\
\hline Visual impairment & $1647^{a}$ & 49 & 52 & 40 & 5 & 5.80 & 4.97 & 17.3 & 274 & 7.5 & 118 \\
\hline Full sight & 2271 & 53 & 55 & 19 & 3 & 4.10 & 4.05 & 7.6 & 170 & 5.7 & 126 \\
\hline$P$ & & $0.004^{b}$ & $<0.001^{c}$ & $<0.001^{b}$ & $<0.001^{c}$ & & & $<0.001^{\mathrm{b}}$ & & $<0.003^{b}$ & \\
\hline No light perception & 251 & 51 & 49 & 47 & 4 & 4.68 & 4.539 & 13.2 & 32 & 5.0 & 12 \\
\hline Light perception & 1329 & 48 & 53 & 40 & 5 & 5.97 & 4.996 & 18.0 & 230 & 7.8 & 100 \\
\hline Full sight & 2271 & 53 & 55 & 19 & 3 & 4.10 & 4.049 & 7.6 & 170 & 5.7 & 126 \\
\hline$P$ & & $0.029^{b}$ & $<0.001^{d}$ & $<0.001^{b}$ & $<0.001^{d}$ & & & $<0.001^{b}$ & & $<0.003^{b}$ & \\
\hline
\end{tabular}

The study investigated a large population of persons with social or practical blindness and showed an enhanced propensity to seasonal variation in emotional and behavioural parameters compared with a population of persons with full sight. Furthermore, in subgroup analysis of the population with visual impairment we found that profoundly blind persons with no conscious perception of light were less susceptible to seasonal malaise than persons with severe visual impairment and maintained light perception but more susceptible than fully sighted control persons.

We thus found that severe visual impairment or blindness increased the risk of winter depression which may support the hypothesis that retinal dysfunction can play a role in the pathogenesis of some cases of SAD. Moreover, our results may suggest that the visual defects involved in affective malfunction exceed the image-forming visual system since both persons with and without conscious light perception were more perceptible to seasonal change than persons with full sight. Decreased light input is no sole actor in the development of SAD and the syndrome most likely arises as an interaction between individual vulnerability (psychological, neurobiological, genetic) and lack of light. In some cases of visual impairment, there is a general reduction in light transduction to the brain and the neural circuitry that sustains normal mood. In seasonally vulnerable persons with visual impairment, the light input in winter may more easily fall below the threshold for maintaining normal mood. One could hypothesise that in profoundly blind persons the light transduction is so massively reduced that the signal of seasonal change is blunted leaving the individual paradoxically less susceptible to seasonal mood swings than a person with less severe visual impairment.
Although a severe visual impairment resulting in a complete disruption of light input may thus protect against seasonal depression, it may lead to increased risk of non-seasonal mood disorder and circadian dysfunction. One hypothesis based on observational and experimental data suggests that glaucomatous damage to the ganglion cell layer leads to more severe disruptions of the circadian system than other ocular conditions causing visual impairments rendering these persons more susceptible to circadian misalignment and possibly other circadian disturbances, e.g. SAD. ${ }^{19}$ The latter question of an association between specific eye disorders and SAD has not been directly addressed but would be a highly interesting extension of our study.

Neither the neuroanatomical substrate involved in depression nor the molecular mechanisms of the beneficial effect of light are fully elucidated. One of the main biochemical theories of depression is still a decreased neurotransmission in the monoaminergic systems. These systems project from perikarya located in the rostral brain stem to the limbic system, especially the amygdaloid complex in the basal forebrain via the medial forebrain bundle. Neuronal in vivo tracing studies have revealed that fibres leave the optic tract to innervate neurons in the medial part of the amygdaloid complex. ${ }^{20} \mathrm{~A}$ recent in vivo tracing study in a transgenic mice model where the melanopsin promoter was encoding the tracer (tau-lacZ) elegantly showed that also the retinal melanopsincontaining axons reach the neurons of the amygdala. ${ }^{21}$ This indicates that this part of the limbic system might be involved in the antidepressant effect of light.

In this survey we were able to screen the majority of Danish persons with visual impairment for seasonality. Despite vast

Table 2 Seasonality in persons with severe visual impairment compared with fully sighted controls

\begin{tabular}{|c|c|c|c|c|c|c|}
\hline & Change in $\mathrm{GSS}^{\mathrm{a}} \mathrm{B}$ & $P$ & $95 \% \mathrm{Cl}$ & $\begin{array}{c}\text { Change in odds for SPAQ } \\
\text { SAD, }{ }^{\mathrm{b}} \operatorname{Exp}(B)\end{array}$ & $P$ & $95 \% \mathrm{Cl}$ \\
\hline \multicolumn{7}{|l|}{ Gender } \\
\hline Male & 0 & & & 1 & & \\
\hline Female & 2.483 & $<0.001$ & 1.150 to 3.810 & 1.415 & 0.001 & 1.154 to 1.736 \\
\hline \multicolumn{7}{|l|}{ Population } \\
\hline Visual impairment & 0 & & & 1 & & \\
\hline Full sight & -1.791 & $<0.001$ & -2.086 to -1.496 & 0.369 & $<0.001$ & 0.299 to 0.456 \\
\hline \multicolumn{7}{|l|}{ Interview method } \\
\hline Mail & 0 & & & 1 & & \\
\hline Telephone & -0.765 & $<0.001$ & -1.089 to -0.441 & 0.677 & 0.001 & 0.035 to 0.856 \\
\hline Age & & & & 0.984 & 0.001 & 0.976 to 0.993 \\
\hline Men & -0.032 & 0.001 & -0.049 to -0.014 & & & \\
\hline Women & -0.066 & $<0.001$ & -0.084 to -0.048 & & & \\
\hline $\begin{array}{l}\text { GSS, Global Seasonality S } \\
\text { a. Results from general lii } \\
\text { b. Results from logistic re }\end{array}$ & $\begin{array}{l}\text { SAD, Seasonal Patter } \\
\text { ion. }\end{array}$ & essment & naire-defined seasonal a & ctive disorder. & & \\
\hline
\end{tabular}


Table 3 Seasonality in persons with no light perception, with maintained light perception or full sight

\begin{tabular}{|c|c|c|c|c|c|c|}
\hline & Change in $\mathrm{GSS}^{\mathrm{a}}{ }^{\mathrm{B}}$ & $P$ & $95 \% \mathrm{Cl}$ & $\begin{array}{l}\text { Change in odds for } \\
\text { SPAQ SAD, }{ }^{b} \operatorname{Exp}(B)\end{array}$ & $P$ & $95 \% \mathrm{Cl}$ \\
\hline \multicolumn{7}{|l|}{ Gender } \\
\hline Female & 2.447 & \multirow[t]{2}{*}{$<0.001$} & \multirow[t]{2}{*}{$1.118-3.775$} & 1.448 & \multirow[t]{2}{*}{$<0.001$} & \multirow[t]{2}{*}{1.177 to 1.782} \\
\hline Male & 0 & & & 1 & & \\
\hline \multirow{4}{*}{$\begin{array}{l}\text { Vision status } \\
\text { No light perception } \\
\text { Light perception } \\
\text { Full sight }\end{array}$} & & \multicolumn{2}{|l|}{0.01} & & \multirow{4}{*}{$\begin{array}{r}0.002 \\
<0.001\end{array}$} & \multirow{4}{*}{$\begin{array}{l}1.282 \text { to } 2.928 \\
2.287 \text { to } 3.545\end{array}$} \\
\hline & 0.592 & 0.05 & -0.003 to 1.187 & 1.937 & & \\
\hline & 1.949 & \multirow{2}{*}{$<0.001$} & \multirow{2}{*}{1.638 to 2.260} & 2.847 & & \\
\hline & 0 & & & 1 & & \\
\hline \multicolumn{7}{|l|}{ Interview method } \\
\hline Telephone & -0.696 & \multirow[t]{2}{*}{$<0.001$} & \multirow{2}{*}{-1.021 to -0.372} & 0.689 & \multirow[t]{2}{*}{0.002} & \multirow[t]{2}{*}{0.543 to 0.875} \\
\hline Mail & 0 & & & 1 & & \\
\hline \multirow{3}{*}{$\begin{array}{l}\text { Age } \\
\text { Women } \\
\text { Men }\end{array}$} & & \multirow{3}{*}{$\begin{array}{l}<0.001 \\
<0.001 \\
<0.001\end{array}$} & \multirow{3}{*}{$\begin{array}{l}-0.086 \text { to }-0.050 \\
-0.053 \text { to }-0.017\end{array}$} & 0.983 & \multirow[t]{3}{*}{$<0.001$} & \multirow[t]{3}{*}{0.975 to 0.992} \\
\hline & -0.068 & & & & & \\
\hline & -0.035 & & & & & \\
\hline
\end{tabular}

attempts of thorough follow-up, a response rate of $59 \%$ rate was reached. We find this satisfactory given the population examined but acknowledge the limitation it poses to our conclusions. We have no information of non-responders besides the $9 \%$ who were dead or ill or otherwise disabled to an extent that did not allow for participation. As a questionnaire-based survey, the study houses other limitations that must be considered. Importantly, the self-report of light perception could be questioned but this information was not otherwise obtainable. In DAB, the current medically assessed visual status of a new member is recorded at registration. This is the only existing comprehensive registration of visual status and the evaluation is performed by an opthalmologist. The majority of DAB members have progressive eye disorders and can thus be expected to have unchanged or worse visual status at the time of our survey. A more exact verification of visual status would require a clinical assessment of all respondents which was not feasible. Moreover, our survey includes no assessment of onset of blindness since in most cases the visual impairment has progressed over time and gives no distinct episode to mark the transformation from mild to severe impairment. A prospective investigation of how progressing or sudden visual impairment influence seasonality could be of great interest and relevance but was not within the scope of this study.

The inherent risk of recall bias in a survey based on self-report will always be present. The survey was performed during the symptomatic period to avoid summertime underestimations of the extent of seasonal variability. Moreover, we believe our methodology allows for comparisons between groups but will refrain from comparisons to previous studies. Clearly, a major advantage of self-report questionnaires is the ability to investigate a large population sample. The two rounds of survey (2010 and 2011) were performed with similar timing during two consecutive winter seasons with similar hours of sunshine according to registrations with the Danish Meteorological Institute.

The validity of the SPAQ is a subject of discussion. Studies have found it acceptable for screening purposes but not as a diagnostic tool since its correlation with current DSM criteria for SAD is uncertain. ${ }^{22}$ Specifically, the SPAQ has been suggested to lack power in separating patients with seasonal depression from patients with non-seasonal depression. In the diagnosis of SAD, DSM criteria exclude persons who have experienced a major depressive episode outside of the expectantly symptomatic season during the past 2 years. Whether this distinct separation of conditions is clinically significant may not be fully definite but it may exclude some persons with a pattern of seasonal malaise from a diagnosis of SAD. Moreover, it seems plausible that DSM and SPAQ criteria may define two distinct phenotypes that are only partly overlapping which may reflect reality quite well. The syndrome of SAD is undoubtedly one end of a broad spectrum of less pathological reactions to the changing seasons and it remains unclear where the demarcation to clinical significance lies. For our study the question of SPAQ validity is of course of great importance since there may be a difference in prevalence of nonseasonal major depression between our populations. However, currently this is not thoroughly documented. ${ }^{23}$ Another problem with the SPAQ is its lack of informant instruction as to which period of time the seasonal change should be assessed, i.e. over how many years the seasonality is to be reported. Whereas the SPAQ is worded in general terms, the DSM SAD criteria include a strict time frame.

Persons with severe visual impairment or blindness may exhibit increased susceptibility to seasonal depressive symptoms due to the increased experience of wintertime barriers to socialisation and physical activities. These factors are undoubtedly of great importance for depressive symptomatology and it must be assumed that wintertime darkness and icy outdoor areas pose greater practical obstacles to persons with reduced vision than persons with full sight. When comparing subgroups with different degrees of visual impairments, a risk of bias lays in the fact that persons with less severe impairments remain dependent on light for orientation, whereas profoundly blind persons are practically unaffected by reduced lighting. It is noteworthy that all members of DAB are medically diagnosed with a vision below 6/60 Snellen visual acuity and must altogether be expected to meet increased difficulties with everyday activities during wintertime due to their significant impairment.

The clinical implications of our study involve the mapping of an affective disorder that has been linked to retinal dysfunction in a population with known eye disorders. Symptoms of SAD are reducible with light therapy but there are no reports of the effect of this treatment in visually impaired populations. There are, however, reports that persons with visual impairment are at risk of sleep disturbances, circadian misalignment and possibly depressive symptoms, although exact prevalence estimations are sparse. $^{23}$ These problems may also be reducible with light therapy, a treatment modality with minimal side-effects. Health professionals who encounter a patient with visual impairment who presents symptoms of depression must pay attention to the possible seasonal content and according to present guidelines consider increased light exposure or actual light therapy as first-line treatment. 
The neurobiological implications include adding an epidemiological piece to the ongoing neuroanatomical and physiological puzzle of connecting the light receptive system to structures and pathways involved in affective homeostasis which is an area currently undergoing vast progress. ${ }^{24,25}$ We find our results of relevance to current knowledge and believe they may generate new and more specific hypothesis to add to the progress to the benefit of patients.

In conclusion, we present the first epidemiological suggestion of a highly significant association between visual status and seasonal variation in mood and behaviour. Our data could support the hypothesis that suboptimal retinal light projection plays a role in the development of SAD and that melanopsin and light-dependent neural pathways may be involved in the pathogenesis of certain affective disorders.

Helle østergaard Madsen, MD, Henrik Dam, MD, Ida Hageman, MD, Psychiatric Center Copenhagen, Copenhagen University Hospital, Copenhagen, Denmark

Correspondence: Helle Østergaard Madsen, MD, Psychiatric Center Copenhagen, Copenhagen University Hospital, dep. 6102, Blegdamsvej 9, 2100 Copenhagen, Denmark.Email: helle.oestergaard.madsen@regionh.dk

First received 16 Dec 2014, accepted 21 Dec 2014

\section{Funding}

The study received financial support from: The Danish Council for Independent Research, Ivan Nielsens foundation, The Max Worner and Wife's foundation, the Augustinus foundation, the foundation of 17.12.1981. None of these held any other role in the project.

\section{Acknowledgements}

The Danish Association of the Blind (DAB) participated in the planning of the practica execution of the study and in the production of audio and Braille font copies of the questionnaire and information letter. Furthermore DAB provided financial support for the study. The study received permission from the Danish Data Protection Agency (journa number 2010-41-4484)

\section{References}

1 Rosenthal NE, Sack DA, Gillin JC, Lewy AJ, Goodwin FK, Davenport Y, et al. Seasonal affective disorder. A description of the syndrome and preliminary findings with light therapy. Arch Gen Psychiatry 1984; 41: 72-80.

2 Molin J, Mellerup E, Bolwig T, Scheike T, Dam H. The influence of climate on development of winter depression. J Affect Disord 1996; 37: 151-5

3 Rohan KJ, Roecklein KA, Haaga DAF. Biological and psychological mechanisms of seasonal affective disorder?: a review and integration. Curr Psychiatry Rev 2009; 5: 37-47.

4 Golden RN, Gaynes BN, Ekstrom RD, Hamer RM, Jacobsen FM, Suppes T, et al Reviews and overviews the efficacy of light therapy in the treatment of mood disorders?: a review and meta-analysis of the evidence. Am J Psychiatry 2005; 162: 656-62.

5 Wehr TA, Skwerer RG, Jacobsen FM, Sack DA, Rosenthal NE. Eye versus skin phototherapy of seasonal affective disorder. Am J Psychiatry 1987; 144: 753-7.
6 Lam RW, Beattie CW, Buchanan A, Remick RA, Zis AP. Low electrooculographic ratios in patients with seasonal affective disorder. Am J Psychiatry 1991; 148: 1526-9.

7 Hébert M, Beattie CW, Tam EM, Yatham LN, Lam RW. Electroretinography in patients with winter seasonal affective disorder. Psychiatry Res 2004; 127: 27-34.

8 Terman JS, Terman M. Photopic and scotopic light detection in patients with seasonal affective disorder and control subjects. Biol Psychiatry 1999; 46: 1642-8.

9 Lavoie M-P, Lam RW, Bouchard G, Sasseville A, Charron M-C, Gagné A-M, et al. Evidence of a biological effect of light therapy on the retina of patients with seasonal affective disorder. Soc Biol Psychiatry 2009; 66: 253-8.

10 Roecklein KA, Wong PM, Franzen PL, Hasler BP, Wood-Vasey WM, Nimgaonkar VL, et al. Melanopsin gene variations interact with season to predict sleep onset and chronotype. Chronobiol Int 2012; 29: 1036-47.

11 Roecklein KA, Rohan KJ, Duncan WC, Rollag MD, Rosenthal NE, Lipsky RH, et al. A missense variant (P10L) of the melanopsin (OPN4) gene in seasonal affective disorder. J Affect Disord 2009; 114: 279-85.

12 Berson DM, Dunn FA, Takao M. Phototransduction by retinal ganglion cells that set the circadian clock. Science 2002; 295: 1070-3.

13 Panda S, Provencio I, Tu DC, Pires SS, Rollag MD, Castrucci AM, et al. Melanopsin is required for non-image-forming photic responses in blind mice. Science 2003; 301: 525-7.

14 Wehr TA, Duncan WC, Sher L, Aeschbach D, Schwartz PJ, Turner EH, et al. A circadian signal of change of season in patients with seasonal affective disorder. Arch Gen Psychiatry 2001; 58: 1108-14.

15 Czeisler CA, Shanahan TL, Klerman EB, Martens H, Brotman DJ, Emens JS, et al. Suppression of melatonin secretion in some blind patients by exposure to bright light. N Engl J Med 1995; 332: 6-11.

16 Rosenthal NE, DellaBella P, Hahn L, Skwerer RG. Seasonal affective disorder and visual impairment: two case studies. J Clin Psychiatry 1989; 50: 469-72.

17 Kasper S, Wehr TA, Bartko JJ, Gaist PA, Rosenthal NE. Epidemiological findings of seasonal changes in mood and behavior. A telephone survey of Montgomery County, Maryland. Arch Gen Psychiatry 1989; 46: 823-33.

18 Madsen HØ, Dam H, Hageman I. Study protocol: a cross-sectional survey of seasonal affective disorder in Danish populations with and without severe visual impairments. BMJ Open 2012; 2: e001020.

19 Jean-Louis G, Zizi F, Lazzaro DR, Wolintz AH. Circadian rhythm dysfunction in glaucoma: a hypothesis. J Circadian Rhythms 2008; 6: 1

20 Cooper HM, Herbin M, Nevo E. Visual system of a naturally microphthalmic mammal: the blind mole rat, Spalax ehrenbergi. J Comp Neurol 1993; 328: 313-50.

21 Hattar S, Kumar M, Park A, Tong P, Tung J, Yau K-W, et al. Central projections of melanopsin-expressing retinal ganglion cells in the mouse. J Comp Neurol 2006; 497: 326-49.

22 Mersch PP, Vastenburg NC, Meesters Y, Bouhuys AL, Beersma DGM, van den Hoofdakker $\mathrm{RH}$, et al. The reliability and validity of the Seasonal Pattern Assessment Questionnaire: a comparison between patient groups. J Affect Disord 2004; 80: 209-19.

23 Nyman SR, Gosney MA, Victor CR. Psychosocial impact of visual impairment in working-age adults. Br J Ophthalmol 2010; 94: 1427-31.

24 Oren DA, Koziorowski M, Desan PH. SAD and the not-so-single photoreceptors. Am J PSychiatry 2013; 170: 1403-12.

25 Van Gelder RN. Non-visual photoreception: sensing light without sight. Curr Biol 2008; 18: R38-9. 